\title{
O sertão em voz alta
}

\author{
The Devil to Pay in the Backlands out loud
}

\author{
Luiza Ely Milano \\ Universidade Federal do Rio Grande do Sul - UFRGS - Porto Alegre - Rio Grande do Sul - Brasil
}

Resumo: O presente texto expõe os resultados de uma experiência de leitura em voz alta do clássico romance roseano Grande sertão: veredas. A leitura em grupo da referida obra deu origem à reflexão que ora será apresentada em três tempos: o texto, a voz e a escuta. Parte-se do destaque dado às marcas de oralidade evidenciadas no texto, aborda-se a singularidade do atravessamento de diferentes vozes na leitura do romance e discute-se o papel da escuta como constitutivo da alteridade e dos sentidos. No percurso do trabalho, o aspecto fônico da língua será destacado a partir de uma abordagem que busca interpretar as relações entre som e sentido no diálogo entre o campo da linguística e o da literatura.

Palavras-chave: Escuta. Fônico. Leitura. Oralidade. Voz.

Abstract: This text presents the results of a reading aloud experience of the classic novel of Guimarães Rosa, The Devil to Pay in the Backlands. The group reading of this work gave rise to the reflection that will now be presented in three parts: text, voice and listening. It begins with the emphasis given to the markers of orality evidenced in the text, then it approaches the crossing of the passage of different voices in the reading of the novel and discusses the role of listening as the basis of otherness and of the senses. In the course of the work, the phonic aspect of language will be highlighted from an approach that seeks to interpret the relationship between sound and meaning in the dialogue between the field of linguistics and that of literature.

Key-words: Listening. Phonic. Reading. Orality. Voice. 
Sou precisamente um escritor que cultiva a ideia antiga, porém sempre moderna, de que o som e o sentido de uma palavra pertencem um ao outro. Vão juntos. A música da língua deve expressar o que a lógica da língua obriga a crer."

Guimarães Rosa, em entrevista a Günter Lorenz.

\section{Introdução}

O presente escrito tem sua origem em sala de aula. Mais especificamente, na sala de aula da disciplina curricular de fonologia. Ao propor aos alunos do curso de licenciatura em letras que realizassem um estudo sobre o comportamento fônico de um material linguageiro que thes interessasse, a professora não imaginava quais seriam os destinos dessa aventura... Este texto, portanto, é uma espécie de testemunho dos efeitos dessa proposta e de alguns de seus desdobramentos. Dentre os desdobramentos está a experiência de leitura coletiva em voz alta do romance Grande sertão: veredas.

Estudar a língua é uma tarefa multifacetada. Aqueles que em algum momento já aceitaram esse desafio sabem bem o quão penoso é decidir por onde abrir a porta desse vasto campo. Exclusões serão inevitáveis e restará sempre a sensação de que algo importante não foi dito. Por esse motivo, e frente a essa inevitável impressão, a reflexão que ora é apresentada baseia-se em uma conhecida máxima saussuriana: o ponto de vista cria o objeto (SAUSSURE, 1977, p. 15). A partir dessa decisão metodológica, será exposto, então, o ponto de partida desde o qual será balizado o presente escrito e o percurso que nele será desenvolvido.

O objetivo inicial é reunir esforços para não ceder à clássica cisão entre linguística e literatura. Essa divisão, recorrente tanto na academia como fora dela, parece ter afastado muitos, em alguns momentos, daquilo que indica ser justamente foco de interesses comuns entre esses dois aspectos complementares do terreno das letras. Desde essa perspectiva, o diálogo entre linguística e literatura determina um modo ao mesmo tempo integrado e arejado de ver os fenômenos linguageiros. Os estudos da linguagem encontram um terreno precioso para suas investigações no âmbito da produção literária. Aliás, pode-se dizer que a literatura diz muito de cada um de nós. Será, então, através da literatura que se buscará dizer algo sobre o funcionamento da língua, com ênfase em seu aspecto fônico, e seus efeitos sobre o falante.

A seguir, será o exposto o detalhamento da experiência de travessia que brotou no texto escrito do romance Grande sertão: veredas, que foi fortemente marcada pela modalidade de leitura em voz alta em grupo e que produziu efeitos a partir da escuta compartilhada. Para desenvolver a presente reflexão, o tema será desdobrado em um percurso dividido em três etapas, quais sejam: o texto, a voz, a escuta.

\section{Desenvolvimento: um percurso de leitura marcado pelo texto, pela voz e pela escuta}

A forma como a obra roseana será aqui abordada se desdobra em três tempos. O ponto de partida é o texto do romance Grande sertão: veredas. Sem dúvida, o fato de ser essa uma obra fortemente marcada pela oralidade não é detalhe. $O$ texto escrito, no entanto, traz já uma inquietação acerca do lugar da voz que nele pulsa. Partindo da oralidade que aparece dilatada para além do texto escrito, em um segundo momento, será abordada a experiência de se colocar em cena a voz. Mas será necessário, já em um terceiro momento, lidar com os efeitos de escuta desse texto que é atualizado pela voz.

\subsection{0 texto}

As marcas do fônico em Grande sertão: veredas são evidentes e estão espalhadas por todo o romance. Há musicalidade, há encadeamento 
poético, há formações neológicas, há provocações fonológicas.

Pode-se perceber que 0 encadeamento melódico, em muitos momentos, produz no texto um efeito de "fala-canto". Passagens como

[...] vem o pão, vem a mão, vem o são, vem o cão. (ROSA, 2001, p. 28)

[...] gente estranha, muito estrangeira, estrangeira inteira. (ROSA, 2001, p. 139)

Diadorim tomou conta de mim. (ROSA, 2001, p. 209)

O que tivesse de ser, somente sendo. (ROSA, 2001, p. 225)

Mas nós passávamos, feito flecha, feito faca, feito fogo. (ROSA, 2001, p. 316)

Um sentir é do sentente, mas o outro é do sentidor. (ROSA, 2001, p. 328)

mostram que rimas, aliterações, ritmo e a própria seleção fonêmica são largamente utilizadas pelo autor como recurso ${ }^{1}$ constitutivo do sentido.

Como diz Tatit, "a voz que fala interessa-se pelo que é dito. A voz que canta, pela maneira de dizer." (TATIT, 2002, p. 15). Tudo leva a crer que o texto de Guimarães Rosa convoca de forma deveras original o dito e o dizer. No texto de Guimarães, a voz que diz quase perde sua função prioritariamente utilitária e a musicalidade da voz cantada acaba por se sobrepor ao aspecto comunicativo. $\mathrm{Na}$ experiência de leitura em voz alta do romance, inúmeras vezes se presentificou uma dualidade oscilante entre o compromisso com a fala mais presa ao texto e o encadeamento quase cantado que atualizava, conforme se verá mais abaixo, a maneira de cada leitor dizer. Assim, os efeitos de sentido iam se deslocando.

Isso porque percebe-se que há, na estrutura do texto, uma constituição fônica muito singular. Tatit (2010, p. 110), ao analisar a obra roseana ${ }^{2}$, aponta que "os fonemas ou as sílabas que poderiam ter valor de signo em contextos particulares conservam, nesse caso, apenas seu valor metonímico em relação à sequência silábica mais ampla.". Ou seja, lá onde o texto escrito costuma prever um elo

\footnotetext{
1 Rónai (2005, p. 36-37) aponta a abundância de aliterações, rimas, onomatopeias e outros elementos de forte potencial sonoro na prosa de Guimarães Rosa.

2 Mesmo que a análise proposta por Tatit (2010) seja relativa ao conto "A terceira margem do rio", pode-se dela extrair consequências que são também evidenciadas em Grande sertão: veredas.
}

associativo nos padrões que fazem encadeamento narrativo da prosa, a escrita roseana resiste, evocando poesia. Resiste e propõe desvios que mesclam os diferentes níveis de análise da língua (fonético, fonológico, morfológico e sintático) de diferentes idiomas ${ }^{3}$, diga-se de passagem, mas que produz um resultado que alterna encantamento eufônico de formas e sentidos e surpresa frente a formações inusitadas.

Uma amostra disso é apresentada por Wisnik (2002, p. 181), em análise de "O Famigerado". O autor aponta que há, nos deslocamentos operados no conto de Primeiras Estórias, um "hesitante devaneio lexical". Para o Wisnik, na instigante passagem

- Vosmecê agora me faça a boa obra de querer me ensinar o que é mesmo que é: fasmisgerado... faz-me gerado... falmisgeraldo... familhas-gerado...? (ROSA, 2005, p.57)

há uma oscilação semântica que provoca o "acidente" neológico. Não há o que contestar na análise primorosa de Wisnik, mas também se pode evidenciar, nesse recorte, que o deslizamento de sentidos é fortemente marcado pelo aspecto fônico da língua. O "acidente" semântico destacado pelo autor é conduzido pelo deslocamento metonímico que ganha um impulso extraordinário na associação fonológica evidenciada nas tramas/armadilhas oferecidas pela rede associativa do léxico do português, guiada pelos efeitos fônicos. Ou seja, a língua não só permite como também impõe a criação de neologismos que são ali evidenciados. Nas palavras de Barthes (2013, p. 15), pode-se dizer que a língua, de forma fascista, obriga a dizer assim, e não de outra forma. O falante ordinário, em nome da clareza da comunicação, passa a vida tentando se esquivar de imposições morfo-fonológicas que the soam impróprias. Tudo indica que Guimarães Rosa, em sua prosa poética, parece não ter temido os riscos do fascismo da língua. Mas também é verdade que ele se valeu do conhecimento de treze idiomas

\footnotetext{
${ }^{3}$ Não é demais lembrar que Guimarães Rosa conhecia bem pelo menos treze idomas.
} 
diferentes para poder burlar as chicanas dessa imposição.

Como bem se pode evidenciar na construção de muitos neologismos presentes no texto, o jogo com a língua é fortemente marcado pela oralidade. Mas não é novidade falar nas formações neológicas na obra roseana. $O$ que vale aqui ainda ser comentado acerca dessa característica no romance é a força fonética e fonológica de muitos dos neologismos encontrados. São formações ancoradas em onomatopeias, em condensações e em escansões. Conforme aponta Rónai (2005, p. 34), o texto roseano carrega, em sua massa sonora, o peso da locução. Ocorrências como "prà-trasado" (ROSA, 2001, p. 74), "f'losofou" (ROSA, 2001, p. 261), "pispissíu" (ROSA, 2001, p. 348) e "dand' ordens" (ROSA, 2001, p. 459) são ilustrativas desse fenômeno.

E é justamente o peso do componente fonológico no texto escrito que merece especial atenção. Encontra-se, no trabalho de Mukarovsky, destaque para a questão do repertório fonêmico mobilizado em produções literárias. O autor chama a atenção para a influência do sistema fonológico sobre composições poéticas, lembrando que

O poeta dispõe do repertório dos fonemas da sua língua. Esse repertório é caracterizado não apenas pelo número dos fonemas e pelas suas relações (fonológicas, acústicoarticulatórias), mas também pela frequência relativa do seu emprego. Ao fazer sua escolha, o poeta pode alterar as relações numéricas dos fonemas, servindo-se de alguns deles com maior ou menor insistência que habitualmente. Ele tem, assim, a possibilidade de deformar, por exemplo, a relação numérica existente entre as consoantes e as soantes, [...] (MUKAROVSKY, 1978, p. 206)

O teórico russo mostra também que, além da escolha dos fonemas, seu agrupamento e sua distribuição, há a entonação, o ritmo e a disposição dos limites das palavras. São esses recursos que servem de aporte linguístico para a análise da forma com que o texto literário encaminha a produção de sentidos.

A partir disso, pode-se dizer que o resultado que a leitura em voz alta produziu foi o de reencontrar no texto uma materialidade fônica que flui de maneiras diversas, ora a partir do encadeamento de elementos melódicos, ora a partir de produções truncadas que surpreendiam o leitor. É possível observar ilustração de ambas ocorrências nas seguintes passagens de Grande sertão: veredas: 1. Foi experimentada fluidez fonêmica em passagens como "E medo meu medi muito maior" (ROSA, 2001, p. 85) ou "E o cavalão, lão, lão" (ROSA, 2001, p. 446); 2. Contrastando trechos com truncamento, como em "fogo-fá, jan-dla-foz" (ROSA, 2001, p. 584) ou em "mexinflól" (ROSA, 2001, p. $609)$.

A oscilação de ritmos produz no texto impactos semânticos significativos que são ampliados pela oralização. A experiência de leitura em voz alta trouxe à tona com grande intensidade essa relação entre fluidez e truncamento que, como será apontado a seguir, passa pela forma como cada um dos leitores empresta sua voz ao texto. Ao atravessar o texto escrito com sua voz, cada um dos leitores do grupo reatualizava, em seu próprio corpo, tempo e espaço, conforme diria Benveniste (1989), as relações entre forma e sentido da língua toda.

E mais, a atualização ou (a inovação) dos contrastes fonêmicos da língua portuguesa indicam ser suporte importante no romance roseano para endereçar à língua questões sobre os padrões fonológicos ali atualizados e/ou renovados. E essa atualização das relações de forma e sentido que foi experimentada através da passagem pela oralização demanda que se justifique o estatuto da leitura do texto em voz alta. É o que será feito a seguir.

\subsection{A Voz}

A leitura em voz alta de Grande sertão: veredas provocou uma experimentação que tangenciou os limites entre oralidade e escrita. As surpreendentes vivências dos efeitos fônicos da língua através da leitura em grupo permitiram a formulação de interrogações acerca do lugar da voz na interpretação do texto literário. Será necessário, então, analisar de que forma a transposição do texto 
escrito para a oralidade ressitua a relação entre sujeito e texto, entre literatura escrita e poéticas orais e a própria relação do leitor com os aspectos fônicos de sua língua materna.

Zumthor (2010, p. 15), em Introdução à poesia oral, diz que a voz interpela o sujeito, imprimindo nele a cifra de uma alteridade. Da experiência em questão - o compartilhamento da leitura em voz alta de Grande sertão - destaca-se a marca da alteridade. Há, na suposição de que o outro divide "de mesma forma" a experiência comigo, a constatação do partilhamento da incompletude. Incompletude do sujeito, incompletude do texto. Afinal, "[...] o texto transmitido pela voz é, necessariamente, fragmentário." (ZUMTHOR, 2010, p. 59, grifos do autor)

Se a imagem de texto que o outro devolve é sempre parcial, restará, na leitura em grupo, compartilhar algo que em princípio não é palpável, ou seja, o aspecto lacunar da linguagem. Será justamente na oscilação entre presença e ausência (do texto, da voz e do outro) que a incompletude do escrito interpelará e ressituará cada um dos participantes da leitura em voz alta. Ao passar o texto pela oralidade, o outro surge bem ali onde ele escapa: no aspecto instantâneo e fugaz da enunciação de sua voz. É novamente a Zumthor que se recorre para interpretar a alteridade experimentada diante do texto:

[...] nele ressoa uma palavra pronunciada, imprecisa, obscurecida talvez pela dúvida que carrega em si, nós, perturbados, procuramos Ihe procurar um sentido. Mas esse sentido só terá uma existência transitória, ficcional. Amanhã, retomando o mesmo texto, eu o acharei um outro. (ZUMTHOR, 2014, p. 54)

A incompletude que é estruturante de qualquer obra literária ganha, assim, na leitura compartilhada em voz alta, valor de testemunho ${ }^{4}$. Aquilo que busca sentido na experiência provocativa com o aspecto fônico da língua - o conjunto de subversões fônicas operadas por Guimarães Rosa é vivido de forma compartilhada. Frente à incontornável incompletude da língua, a leitura

\footnotetext{
4 Testemunho aqui tem o sentido proposto por Agamben (2008,
} p. 25) atravessada pela voz suscita uma apreensão do sentido cuja originalidade é a possibilidade de comungar o não saber absoluto sobre a língua. Aquilo que cada um dos leitores experimenta remete à possibilidade de o parceiro também vivenciar. Afinal, conforme lembra Zumthor,

[...] percebemos o peso das palavras, sua estrutura acústica e as reações que elas provocam em nossos centros nervosos. Essa percepção, ela está lá. Não se acrescenta, ela está. É a partir daí, graças a ela que, esclarecido ou instilado por qualquer reflexo semântico do texto, aproprio-me dele, interpretando-o, ao meu modo; é a partir dela que este texto, eu o reconstruo, como o meu lugar de um dia. (ZUMTHOR, 2014, p. 55)

É esse lugar de um dia, ou seja, a fugaz posição desde a qual cada um dos leitores se apropria do texto via voz, que atualiza o contraste entre o mesmo texto evocado de formas diversas por vozes distintas. Há nesse momento o compartilhamento da experiência do mesmo (o "mesmo texto" sendo lido por todos) através do diferente (formas absolutamente singulares de atravessar o texto com entonação, prosódia e realizações fonéticas próprias). Talvez seja justamente pelo fato de o Grande sertão apresentar uma escrita tão marcada pela oralidade que torne a experiência da alteridade excepcionalmente significativa na leitura em voz alta. A subversão é a marca desse texto e o leitor atualiza um tanto dessa subversão através da voz. No entanto, há uma característica que ainda merece ser melhor analisada: a questão do testemunho, do compartilhamento. É momento de dar passagem à questão da escuta.

\subsection{A Escuta}

A voz que brotava no texto de Guimarães Rosa ganhava contornos diferentes ao passar pela performance de cada um dos leitores do grupo. Como destaca Zumthor, cada performance nova coloca tudo em causa (ZUMTHOR, 2014, p. 36). Mas é também nessa mesma obra que o autor fala em audição performativa (ZUMTHOR, p. 44). Essa expressão parece dizer algo da experiência 
vivenciada na leitura em voz alta, pois a percepção que circula suscita uma presença no leitor (ZUMTHOR, p. 78). No entanto, conforme foi sublinhado acima, a presença nunca é plena, pois a voz que se escuta não confirma nada daquele que lê, nem do texto.

Ao se ler em voz alta, a voz se desprende do corpo e se empresta ao outro. Ela ecoa feito pura alteridade. Assim ela segue até fazer efeito na escuta do outro. O texto lido em voz alta se transforma ao passar pela voz de cada leitor e é reatualizado na escuta de cada um. Nesse sentido, pode-se dizer que a voz provoca duplamente o texto. Provoca e desloca na performance oral de cada um dos leitores e opera sobre a percepção ${ }^{5}$ singular que a alteridade evoca. Mais uma vez merecem destaque as palavras de Zumthor (2014, p. 84), "A leitura torna-se escuta, apreensão cega dessa transfiguração, [...]".

A experiência de leitura partilhada também surpreendeu na forma renovadora com que alguns instigantes lapsos foram cometidos. A evocação de fonemas, sílabas e palavras equivocadas não raras vezes provocava um misto de surpresa e regozijo no grupo. Experimentar as subversões de Guimarães Rosa de forma partilhada em alguns momentos chegou a produzir uma verdadeira conivência subversiva, mas "subverter a subversão" foi ainda mais impactante. A alteridade em jogo na cena da leitura em voz alta evocava algo como um desejo e, por que não ousar dizer, a necessidade de experimentar uma forma muito singular de subversão. Encontramos nas palavras de MerleauPonty uma possível explicação para isso:

[...] a percepção ilusória não pode apoiar-se nos "dados presentes", já que eu leio "almoço" ali onde o papel traz "alvoroço". A letra $m$, que se substitui ao grupo vor, não sendo fornecida pela visão, deve vir então de outro lugar. Dirse-á que ela vem da memória. [...] Mas só depois a experiência passada pôde aparecer como causa da ilusão, foi preciso que a experiência presente primeiramente adquirisse forma e sentido para fazer voltar

\footnotetext{
5 Não é objetivo do presente trabalho aprofundar as diferenças existentes entre os conceitos de "percepção" e de "recepção". Para maior detalhamento desses temas, sugere-se a leitura de Merleau-Ponty (2011) e Zumthor (2014).
}

justamente esta recordação e não outras. (MERLEAU-PONTY, 2011, p. 45, grifos do autor)

Merleau-Ponty aponta para a experiência que passa pelo contraste entre percepção e ilusão que, no caso da leitura em voz alta, tinha o acréscimo do compartilhamento da experiência em grupo. A recordação/memória vivenciada em companhia do outro sublinhava insistentemente o efeito de escuta produzido a partir do texto. Nesse sentido, o amparo do grupo indicava uma espécie de suporte daquilo que brotava no texto, transformava-se na voz e era constatado via escuta. Há, nesse percurso, a reedição de uma relação com a língua que evoca a experiência apontada por Freud como "estranhamente familiar".

Em O estranho6, Freud (1981) fala dos sentidos antagônicos contidos em representações dissimuladas. Há diversas formas de atualização dessa dupla vida do sentido, e a literatura é uma delas. Freud, no referido ensaio, ilustra, a partir do conto fantástico de Hoffmann "Der Sandmann", o quanto o inconsciente é estruturalmente duplo, e que esse duplo condensa algo simultaneamente familiar e estranho. Trata-se daquela categoria do assustador que remete ao que é conhecido e íntimo, mas ao mesmo tempo espanta por não ser reconhecido imediatamente como familiar (FREUD, 1981, p. 2484).

Nesse sentido, pode-se apontar aproximações entre o estudo de Arrigucci Júnior (1994) e a interpretação aqui sugerida. O autor, ao analisar as marcas da tradição oral no romance roseano, destaca que nele há criações de linguagem que geram uma "[...] mescla única, difícil de definir e de entender num primeiro momento, que estranha e surpreende e vai, entretanto, se apoderando do leitor, à medida que se entrega ao fluxo rítmico da narrativa também misturada." (ARRIGUCCI JÚNIOR, 1994, p. 13).

A leitura em voz alta de Grande sertão: veredas produziu uma experiência de escuta do "estranhamente familiar" na ordem da língua. Aliás,

\footnotetext{
6 Das unheimlich, no original alemão, de 1919. Para o presente estudo foi utilizada a versão em espanhol intitulada Lo siniestro (cf. FREUD, 1981).
} 
o encontro com o "estranhamente familiar" foi um dos pontos mais impactantes da aventura de leitura em voz alta. A travessia do já familiar terreno da língua, garantido pelo texto notoriamente reconhecido como cânone da literatura brasileira, não foi sem surpresas. A forma com que cada integrante atualizava o texto em sua voz produzia, ao mesmo tempo, conforto e inquietação. A troca de um fonema, de uma palavra, uma entonação inesperada, uma acentuação lida de forma subversiva e até mesmo inversões sintáticas realizadas pelos leitores no momento da experiência colocavam em cena, na escuta partilhada, o malestar frequente do "estranhamente familiar". Ao mesmo tempo em que havia um deleite produzido pelo encontro com o outro nas veredas do texto de Guimarães Rosa, produzia-se uma repentina surpresa frente à irrupção de lapsos que atualizavam o texto, via voz, de maneira absolutamente original. Ao compartilhar-se com a voz a irrupção do inusitado em um texto fortemente marcado pela subversão, produzia-se, a cada vez, efeitos surpreendentes. De fato, de uma travessia não se sai da mesma forma com que se entrou.

\section{Conclusão}

Este trabalho representa o registro de uma experiência ${ }^{7}$. É ele, portanto, um texto tecido a partir de efeitos. O percurso nele trilhado buscou destacar em três tempos os elementos que marcaram a trajetória de leitura em voz alta em grupo do romance de Guimarães Rosa Grande sertão: veredas.

O ponto de partida foi o texto. Não é novidade apontar a característica de prosa-poética da escrita de Guimarães Rosa. Mas foi importante destacar o transbordamento do aspecto fônico da língua que o faz soar fortemente poético. Seu encadeamento rítmico, entonacional e as rimas, no entanto, contrastam com ocorrências fonicamente truncadas ou complexas, que igualmente colocam em cena

\footnotetext{
7 O livro foi lido em encontros semanais, em um período de nove meses (entre março e novembro de 2015).
}

reatualizações das relações entre som e sentido na língua.

Essas relações são fortemente abaladas quando se encara o desafio de submetê-las à voz. $\mathrm{Na}$ medida em que cada um dos leitores emprestava sua voz ao texto roseano, o romance todo era ressituado. A voz, além de funcionar como um operador de renovação do texto escrito, produzia efeitos compartilhados de interpretação da obra. A cada sessão de leitura, resgatava-se algo do que Zumthor (2014, p. 58) chama de "nostalgia da voz", uma necessidade de atualizar os sentidos pela via da alteridade. O caráter efêmero da voz era sempre contrastado com a permanência do texto escrito, mesmo quando tensionava de forma inusitada as relações entre som e sentido.

É por esse motivo que se destacou a importância do compartilhamento via escuta: a fluidez e o truncamento do texto evocavam inquietantes efeitos no ouvinte. Subverter a língua com e a partir do romance de Guimarães Rosa produziu efeitos ao mesmo tempo íntimos e estranhos. Reconhecer na própria língua o estatuto de uma alteridade que encanta e assusta ao mesmo tempo desacomoda e convida à experimentação do novo. Novas vozes, novos sentidos. Sem dúvida, em parceria a travessia foi outra.

\section{Referências}

AGAMBEN, Giorgio. O que resta de Auschwitz. 1. ed. São Paulo: Boitempo, 2008.

ARRIGUCCI JÚNIOR, Davi. O mundo misturado: romance e experiência em Guimarães Rosa. Novos Estudos Cebrap. São Paulo, n. 40, p. 7-29, novembro 1994.

BARTHES, Roland. Aula. São Paulo: Cultrix, 2013.

BENVENISTE, Émile. A forma e o sentido na linguagem. In: BENVENISTE, Émile. Problemas de linguística geral II. 1. ed. Campinas: Pontes, 1989. p. 220-242.

FREUD, Sigmund. Lo siniestro. In: FREUD, Sigmund. Obras Completas. Tomo III. Traduzido por LopezBallesteros. Madri: Biblioteca Nueva, 1981. p. 2483-2505. 
LORENZ, Günter W. Diálogo com Guimarães Rosa. In: COUTINHO, Eduardo F. (Org.). Guimarães Rosa. 2. ed. Rio de Janeiro: Civilização Brasileira, 1991.

MERLEAU-PONTY, Maurice. Fenomenologia da percepção. 4. ed.. São Paulo: Martins Fontes, 2011.

MUKAROVSKY, Jan. A Fonologia e a Poética. In: TOLEDO, D. (Org.). Círculo Linguístico de Praga: estruturalismo e semiologia. 1. ed. Porto Alegre: Globo, 1978. p. 204-214.

RÓNAY, Paulo. Os vastos espaços. In: ROSA, João Guimarães. Primeiras estórias. 1. ed. especial. Rio de Janeiro: Nova Fronteira, 2005. p. 19-47 .

ROSA, João Guimarães. Grande sertão: veredas. 19. ed. Rio de Janeiro: Nova Fronteira, 2001.

Primeiras estórias. 1. ed. especial. Rio de Janeiro: Nova Fronteira, 2005.

SAUSSURE, Ferdinand de. Curso de linguística geral. 8. ed. São Paulo: Cultrix, 1977.

TATIT, Luiz. O cancionista. 2. ed. São Paulo: Edusp, 2002.

Semiótica à luz de Guimarães Rosa. 1. ed. São Paulo: Ateliê Editorial, 2010.

WISNIK, José M. O famigerado. Scripta. Belo Horizonte, v. 5, n. 10, p. 177-198, 1ํsemestre 2002.

ZUMTHOR, Paul. Introdução à poesia oral. 1. ed. Belo Horizonte: Editora UFMG, 2010.

Performance, recepção, leitura. 1. ed. portátil. São Paulo: Cosac Naify, 2014.

\section{COMO CITAR ESSE ARTIGO}

MILANO, Luiza. O sertão em voz alta. Signo, Santa Cruz do Sul, v. 42, n. 74, maio 2017. ISSN 1982-2014. Disponível em: <https://online.unisc.br/seer/index.php/signo/article/view/8677>. Acesso em: doi: http://dx.doi.org/10.17058/signo.v42i74.8677. 